\title{
Entomological citizen science in Canada
}

\author{
John H. Acorn ${ }^{1}$
}

\begin{abstract}
Citizen science involves voluntary participation in the scientific process, typically by gathering data in order to monitor some aspect of the natural world. Entomological citizen science, as an extension of traditional amateur entomology, is an active field in Canada, with online databases such as eButterfly and BugGuide attracting both contributors and database users. As well, traditional amateur entomology continues to be important in Canada, as do short-term insect-themed educational events, the involvement of amateurs in entomological societies, and online crowdsourcing initiatives. Success of citizen science projects can be measured in many ways. In terms of published papers that analyse trends in citizen science data, Canadian projects have only begun to deliver. More valuable are particular records that improve our knowledge of geographic ranges and phenology. In terms of the endurance of particular projects, and the willingness of volunteers to participate, citizen science entomology in Canada is clearly a success. However, quality control of citizen science data remains an issue for some projects. As well, challenges remain with respect to balancing the goals of researchers, participants, and supporting institutions.
\end{abstract}

\section{Introduction}

Over the past two decades, entomologists have shown an increased interest in the process we now call "citizen science". The idea that non-scientist volunteers are willing to collect scientific data, and to make that data available to researchers, has great appeal. Here, I will review the diversity of entomological citizen science projects in Canada, including many that are broader in scope but involve Canadian participation. I will also comment on the relative successes and failures of these various projects, and attempt to identify aspects that characterise successful and enduring initiatives.

There is no official definition of citizen science, perhaps because the concept is more social than scientific, and those who have attempted to define it have been concerned primarily with how citizen science "democratises" the scientific process (e.g., Pocock et al. 2012), and/or empowers environmental activism (e.g., Mueller et al. 2012). Citizen science is conducted by "citizens", in the sense that neither formal training, nor employment in the sciences, are required in order to participate. Citizen science can be seen as a subcategory of science proper, in the sense that it involves the gathering of data, even though participants may not be involved in the other activities that characterise science as a whole. Traditionally, we think in terms of a data-gathering component of science, a data analysis component of science, and an interpretive "discussion" component of science. As well, the scientific method is typically thought of as being hypothesis driven (with the hypothesis or "question" preceding data collection), and in mainstream science the process of generating and testing hypotheses is the domain of the researchers - those people who are unequivocally "scientists". In citizen science, the participants are almost exclusively involved in data gathering alone, but most projects include the promise that anyone is welcome to follow through with their own analyses and interpretations. This is the key element that makes citizen science "democratic", even if a few participants follow up with analyses of their own. "Citizen Scientist" is, therefore, best understood as an honorary title, given to anyone who participates in any level of the scientific enterprise, on a voluntary basis, with the proviso that most participants are involved only in data collection.

In entomology, citizen science data typically "monitors" some aspect of the insect world.

Received 2 June 2017. Accepted 24 July 2017. First published online 6 October 2017.

J.H. Acorn, ${ }^{1}$ Department of Renewable Resources, University of Alberta, Edmonton, Alberta, T6G 2H1, Canada

${ }^{1}$ Corresponding author (e-mail: jacorn@ualberta.ca)

Subject editor: Héctor Cárcamo

doi:10.4039/tce. 2017.48 
For natural history subjects in general, what is monitored typically involves changes in distribution, abundance, or phenology. Some authors have used the term "participatory monitoring" to characterise this process (e.g., Bell et al. 2008).

\section{The variety of entomological citizen science in Canada}

In one classification of citizen science projects (Wiggins and Crowston 2011), five categories were identified, focussing on (1) socio-political action on local environmental issues, (2) conservation projects, stewardship, and monitoring, (3) real-world scientific investigation of particular questions, (4) virtual scientific investigation of particular questions, and (5) education and outreach. Of these, entomological citizen science in Canada has focussed primarily on categories (2), (3), (4), and (5), with most projects falling into (2) or (5). However, I find these categories less "mutually exclusive" than do Wiggins and Crowston (2011), and for this reason I will adopt my own ad hoc classification in the following account. I note as well that not every member of the general public who participates in programmes initiated by professional scientists is automatically a "citizen scientist". It seems unwise, for example, to include those who engage in the planting of flowers for butterflies and bees as citizen scientists. Or to include those involved in environmental advocacy, for example in defense of pollinators, even if they are motivated by scientific arguments. These people are not gathering data, or recording observations, and as such they cannot be considered participants in a scientific process per se.

\section{Traditional amateur entomology}

Since before the Canadian nation state existed, there have been insect collectors here, many of whom have been amateurs. In retrospect, many of these collectors deserve recognition as citizen scientists (Miller-Rushing et al. 2012). The term "citizen science" was coined to accommodate the emergence of large online databases in recent decades, and not because the role of amateurs has changed in other significant ways. If amateurs in the past labelled their specimens properly (with location, date, and collector's name) they can be said to have gathered scientific data, and their data can be used to monitor at least some aspects of the species involved. Most museum-oriented entomologists would agree, however, that to fully qualify as citizen scientists, a collector must have made their collection available for study to other interested individuals, or donated/willed their collection to a public institution. However, the history of amateur contributions to entomology has unfortunately been characterised by a struggle between the desire to be seen as contributing to the broader goals of science on the one hand, and the accumulation of personal, closely guarded treasure troves on the other.

In similar fashion, many amateur naturalists keep field notes, and produce photographs, both of which can be considered data when sufficient attention to detail and accuracy has been made. Many modern cameras and smartphones encode date, time, and GPS coordinates into photographic metadata, making data collection of this sort automatic. In the days of film-based photography, however, photographs needed to be labelled by hand, if they were labelled at all. Like collections of specimens, such personal records have, on occasion, been accepted as donations to public institutions (in this case archives, libraries, or museums) where they become generally available for study and analysis. Data from collections, field notes, and photographs have been incorporated into modern citizen science databases, and the desirability of historical or "baseline" data makes the contributions of these amateurs especially valuable.

\section{Short-term public events}

Many citizen science projects involve one-day or multi-day events, during which some aspect of the insect fauna is also counted, or surveyed, with the help of members of the general public. Examples include butterfly counts, "bioblitzes", festivals, and National Moth Week. These are mostly educational events, but they do attempt to contribute to monitoring and the collection of scientific data.

One-day butterfly counts began in North America as "Fourth of July Butterfly Counts", initiated by the Xerces Society in 1974 (Pyle 1984), inspired by the popularity of Christmas Bird Counts, coordinated by the Audubon Society and initiated by Frank Chapman in 1900 (LeBaron 2007). The North American Butterfly Association (NABA) now compiles data from these counts, where they are now known simply 
as "butterfly counts". However, the number of butterfly counts in Canada has declined in recent years (e.g., in Alberta, Canada the number has dropped from more than 40 in 2000 to about five today), in part because of the realisation that data from one year cannot be directly compared with data from other years due to the confounding influence of phenology. Compilers and participants in butterfly counts seem interested in monitoring butterfly abundance, but the data they gather typically compares the peak emergence of a species in one year with the beginning or end of the emergence of the species in another year. In contrast, phenology is not a major issue for Christmas Bird Counts, since birds are long lived, and most birds are not migratory during the mid-winter count period, although some are indeed irruptive.

Another reason for the apparent decline in butterfly counts may be that the results of these counts are not made available online (although they are, according to the North American Butterfly Association website, available on request to scientists conducting research), and participants are charged a fee to participate in counts, as with Christmas Bird Counts. The North American Butterfly Association does, however, archive incidental sightings online, at https:// sightings.naba.org. Many counts exist that do not send their data to the North American Butterfly Association, although the data may be submitted or published elsewhere (e.g., Bird 2016). The primary value of butterfly counts is, therefore, to increase appreciation of butterflies and their diversity, although long-term accumulation of butterfly count data does indeed produce some interesting records, such as range extensions or unusual abundances.

"Bioblitzes" involve the detection and identification of insects, and other organisms as well. They are typically one-day or one-time events, although some are spread over a few days. Experts on the identification of various groups are invited to participate, often assisted by volunteers. The stated objective is to quickly survey the fauna of a particular area, as a "snapshot". The term "snapshot" acknowledges the importance of phenology, without solving the issues that phenology creates. BioBlitz Canada 150 (http://bioblitzcanada.ca) is a new and typical example, "noting all the existing species - and perhaps discovering new ones! It's Canada's 'nature selfie', and you're invited!"
Of course, no such activity could hope to identify all of the species in an area, and like butterfly counts, the main value of bioblitzes lies in promoting awareness of the diversity of life. Still, as with any natural history outing, the potential for interesting discoveries is real, and significant finds are indeed made, including new species, and range extensions.

Insect-themed festivals, by that name or any other, are also intended to promote appreciation and awareness. Typically, these events occur in nature centres, science centres, or similar facilities. At the Ellis Bird Farm, in Alberta, for example, the annual Bug Jamboree involves a number of professional and amateur entomologists, with presentations and exhibits. I sing insect-themed songs to begin the event, and Charles Bird leads a butterfly count walk to end it off. Festivals are educational events more than data-gathering events, although they may include some aspect of the latter.

Another example, National Moth Week (Moskowitz and Haramaty 2013) is an online attempt to coordinate and encourage mothappreciation events worldwide, during a designated week-long period in mid-summer. Canadian participation in this international event has been relatively high, with 15 registered events, second only to the United States of America with 245 events (Moskowitz and Haramaty 2013). One stated objective of this programme is to produce a global moth database, but like other short-term events, it seems clear that its primary function is educational, and promotional. Finally, there is also a School Malaise Trap Program (http:// malaiseprogram.com/) whereby schools are provided with Malaise traps to use in their schoolyards, free of charge, and the specimens are sent to the Centre for Biodiversity Genomics at the University of Guelph, in return for a report on what they found (sample reports are available on their website).

\section{Online database projects}

Projects that result in a publically accessible database (typically online, and open-access) characterise the essence of modern citizen science. So-called "atlases" (typically presented in print form, as species by species dot maps and phenological histograms) are the historical precursors of such projects, and like butterfly 
counts they appear to have been inspired by ornithological projects of a similar nature. Butterflies, especially, have been the subjects of atlasing projects for such regions of Canada as Ontario (www.ontarioinsects.org/atlas_online. $\mathrm{htm}$ ), the Maritimes (www.accdc.com $/ \mathrm{mba}$ / index-mba.html), and British Columbia (www. bcbutterflyatlas.ca). Typically, the region being atlased is overlain by a map grid $(10 \times 10 \mathrm{~km}$ is standard), and thereby divided into "atlas squares". Then, volunteer participants attempt to visit as many squares as possible, and survey the butterflies therein. This naturally requires multiple visits to the same square, because of phenological changes in the butterfly assemblage through the season.

In more traditional examples of atlases, the end product is a book (e.g., Holmes et al. 1991), while newer atlasing projects present their results online. Traditionally, atlasing projects occur over a prescribed duration (e.g., five years) before the finished product is announced, but increasingly, they are open-ended, with maps and other data summaries continually updated online. Butterfly atlases differ from other open-ended butterfly databasing projects only in the sense that they encourage participants to visit all of the squares on the atlasing grid. Other insect groups have not been the subjects of atlasing projects in Canada, simply because such efforts require large numbers of participants over broad geographic regions. Outside Canada, however, there are atlasing projects for such faunas as the Syrphidae (Diptera) of the United Kingdom (Ball and Morris 2000) and the Odonata of the United Kingdom (https://british-dragonflies. org.uk/content/national-dragonfly-atlas).

The most successful online butterfly databasing project in North America is eButterfly (Prudic et al. 2017), an initially Canadian effort inspired by the highly successful citizen science ornithology project eBird, hosted by the Cornell Laboratory of Ornithology (Ithaca, New York, United States of America) (Bonney et al. 2009; Sullivan et al. 2014). eButterfly, in turn, contributes records to iNaturalist Canada, coordinated by the Canadian Wildlife Federation. iNaturalist is an international project that bills itself as "a community for naturalists" (www.inaturalist.org), coordinated by the California Academy of Sciences (San Francisco, California, United States of America), and currently with over five million records, some of which are based on photographs and are thus considered "research grade". Many other citizen science projects share records with iNaturalist, and in turn iNaturalist shares records with the Global Biodiversity Information Facility.

Originally, eButterfly was the brainchild of Maxim Larrivée, as a doctoral student with Jeremy Kerr at the University of Ottawa in 2011. The project has now expanded to include the United States of America. For each province and state, expert lepidopterists volunteer to vet incoming observations, which may or may not include photographs, field notes, or sketches. Compared to eBird, eButterfly is much smaller in scope. However, the eBird team has been extremely helpful and supportive of eButterfly, sharing technical knowledge as well as insights into their successes and failures. The main theme that has emerged from this dialogue has been the importance of making the database useful to naturalists for their own purposes (Prudic et al. 2017). In other words, the administrators at eBird learned that birders have limited motivation to "help the scientists", but significant motivation to keep track of their own sightings, photographs, and lists (including the all-important "life list" of all species seen by a particular birder). eButterfly has emulated this aspect of eBird, and butterfly watchers are motivated by many of the same concerns as birders. One key component of eButterfly is its "checklist approach", whereby observers report all of the butterflies seen during an outing, thereby providing presence and presumed-absence data, of a sort that is more useful in ecological analyses than incidental records of noteworthy individual butterflies.

There are other butterfly-related database projects with Canadian participation. In general, butterfly-based citizen science projects group neatly into those that are motivated by the enthusiasm of naturalists for lists and field notes, and those that are based on conservation concerns. Many conservation-based projects focus on a single species. The Pieris Project (www.pieris project.org), for example, encourages participants to send specimens of cabbage white butterflies (Pieris rapae (Linnaeus); Lepidoptera: Pieridae) to a central coordinator, for use in an "awesome science" project, in which a large team of researchers plan to examine global patterns in DNA sequence differences in this widely introduced species. 
The most popular species of butterfly for citizen science, however, is clearly the monarch (Danaus plexippus (Linnaeus); Lepidoptera: Nymphalidae), because of its iconic nature, and public concerns about the future of the monarch's annual multigeneration migration to and from Mexico. Some see the monarch as an insect "flagship species" (Guiney and Oberhauser 2008). Monarch Watch (www.monarchwatch.org) is one such project, and its primary goal involves tagging monarchs in the United States of America and Canada, in the hopes that these tags will be recovered on the overwintering grounds. Large numbers of these tags are indeed relocated. The director of Monarch Watch is Orley "Chip" Taylor, at the University of Kansas (Lawrence, Kansas, United States of America). The Monarch Larva Monitoring Project (Oberhauser and Prysby 2008), coordinated at the University of Minnesota (Minneapolis, Minnesota, United States of America), encourages participants (the "research army") to collect wild monarch larvae, rear them, and report on whether they survived or succumbed to parasites. Project Monarch Health (www.monarchparasites.org) is similar, but focussed on the collection (from adult monarchs in a harmless fashion, by pressing tape against the butterfly to collect spores), of samples of the gregarine parasite Ophryocystis elektroscirrha McLaughlin and Myers (Neogregarinorida) (OE) by volunteer participants. Workers at the University of Georgia (Athens, Georgia, United States of America) coordinate Project Monarch Health. All single-species-focussed projects appear to rely heavily on participation by school children, and other organised groups.

Few other insect taxa are popular enough to have inspired projects of their own, but the Odonata are an exception. Odonata Central (www.odonatacentral.org) deserves mention here, as a portal for data on damselflies and dragonflies. This site provides regional checklists, species distribution maps, an extensive gallery of photographs, and a database of close to 150000 individual records. In Canada, the Atlantic Dragonfly Inventory Project is another active initiative, coordinated by Paul Brunelle and supported primarily by amateur naturalists (http:// birdingnewbrunswick.ca/forum/topics/atlanticdragonfly-inventory-program-adip-participating and www.odonatanb.com).
Perhaps the most important development in entomological citizen science in North America is "BugGuide.Net" or simply "BugGuide" (http:// bugguide.net). This is an online portal for photographs of insects and other arthropods, focussing on North America. Photographs undergo a vetting process, and a great number of expert insect taxonomists contribute voluntarily to the vetting process. The website is arranged according to current taxonomy, and this taxonomy is continually being updated. For each species or terminal taxon, the best quality images are retained and displayed, while poor or unidentifiable photos are relegated to a category entitled "frass", and eventually deleted. As well as the photographic guide, the site also provides identification and natural history information, and is the host of a number of related forums, where issues of identification, taxonomy, website design, and photography are actively discussed. In-person workshops and gatherings are also held, all so far in locations in the United States of America. Without exaggeration, it is clear that BugGuide has become the single most heavily used identification resource for arthropods in North America. BugGuide does not, however, place itself in competition with more traditional books and papers, and references and links to relevant literature are provided for most taxa. Because of the impressive volume of photographic contributions, and the continual scrutiny of the photographs by experts, interesting discoveries, including range extensions, new associations and behaviours, and even new species, are being made (Cannings et al. 2007; Hamilton 2011; Carlson et al. 2012).

Additional sites focus on concern for bees and other pollinators, and concerns about the effects of introduced species. With respect to pollinators, the most prominent project is probably Bumble Bee Watch (www.bumblebeewatch.org). With multiple partners and collaborators, this project solicits photographs of bumble bees (Bombus Latreille; Hymenoptera: Apidae), which are then identified by experts, after which the data are added to a database and plotted on maps. The goal is to monitor or "track" these bee species in North America, motivated by the decline of such species as Bombus affinis Cresson and Bombus occidentalis (Greene) (Grixti et al. 2009; Colla and Ratti 2010). The results are impressive, 
especially given the difficulty that even experts have when identifying Bombus from photographs. The collaboration of multiple experts helps ensure that no one individual becomes overly complacent with their taxonomic determinations. Bumble Bee Watch, in collaboration with Friends of the Earth, has recently initiated a Great Canadian Bumble Bee Count, as a one-day annual event (https:// foecanada.org/en/issues/bumble-bee-count).

The monitoring of introduced species is typically framed by the "invasion" metaphor, and one recent example is the Early Detection and Distribution Mapping System (www.eddmaps. org), a United States of America project that also solicits Canadian participation. The concept is simple: citizen scientists report the presence of invaders, and the information is thereby made available to the authorities, who are then able to follow through with appropriate control measures. From an economic entomology perspective, such a database is clearly justified, but it is not clear that such is the case from a biodiversity conservation standpoint, where a fascinating debate has arisen, centred around the degree to which socio-political metaphors (e.g., "invasion" as a military metaphor, for a purely ecological phenomenon) are biasing the attitudes of conservation biologists toward introduced species (e.g., Davis and Chew 2017; Russell and Blackburn 2017).

In Canada in the 1990s, the Canadian Nature Federation launched an early citizen science project called the Ladybug Survey, promoted to schools and naturalist groups through its magazine. This project resulted in 32579 records, which were mapped and displayed on a short-lived website. Identification errors were rampant in the dataset, and the maps and website were soon removed. This project appeared to be based on the notion that monitoring an "invader" somehow helps control it, but it is clear that the project did nothing to reduce the spread of introduced Coccinellidae (Coleoptera) in Canada (Acorn 2007). Centred in the United States of America, the even more ambitious Lost Ladybug Project appears to have been more successful in monitoring both introduced and native species, and the organisers may have learned valuable lessons from the experiences of their Canadian predecessors, focussing on the excitement of rediscovering "lost" species that became uncommon following the arrival of introduced species (Losey et al. 2012).

\section{Clubs, societies, and social media groups}

If citizen science is defined in the broad sense, then it surely includes the participation of amateurs in entomological societies and clubs. All such groups, to my knowledge, encourage participation by amateurs, but some are more successful than others. Very few amateurs, for example, have an interest in agricultural or medical entomology, and those societies that focus heavily on such applied fields have limited amateur buy-in. However, many amateurs do indeed have an interest in taxonomy and faunistics, and to the extent that they possess the statistical and theoretical training necessary in order to understand the relevant analyses, they are interested in ecology and behaviour as well. In a large scientific society, with concurrent sessions at its annual meetings, it is easier for amateurs to connect only with what interests them, but there is a trade-off between access to relevant presentations and the costs of both membership and conference registration. Thus, smaller, more local societies seem to attract the largest proportion of amateurs, since participation in these societies is more affordable.

One such example of a local society with many amateur members is the Toronto Entomologists' Association. Others include the many provincial entomological societies. An even more tightly focussed group is the Alberta Lepidopterists' Guild, which I discuss here in order to highlight two other aspects of citizen science: group projects and social media. In 2015, after exploring the possibility of undertaking a butterfly atlas project for Alberta, the Alberta Lepidopterists' Guild decided instead to encourage local participation in eButterfly. In addition, the "Alberta Butterfly Roundup" was initiated, in the spring of 2015. This project encourages participants to re-confirm all of the species of butterflies known from Alberta, and is ongoing and open-ended. In 2015, 122 species were confirmed (and one species was added to the provincial list), and an additional 14 were documented in 2016, leaving 32 still to be relocated (Acorn 2016). A spirit of friendly competition motivates the group, and the project reminds participants that the presence of a species on an official checklist does not necessarily mean that the species continues to exist in the region.

In the Alberta Butterfly Roundup example, participants were encouraged to submit their 
records in any of a number of ways (although eButterfly was promoted as the best). Many, however, were most comfortable using the e-mail list-server, Albertaleps. For those who are leery of social media, the list-server is their virtual society. Others, however, preferred the Facebook page. Still others were reluctant to expose their photographs to general scrutiny, and sent their records directly to me, as compiler. Still others chose the most traditional "portal" of all, and showed me their specimens in person. Realising that many interesting records were being lost to eButterfly, the eButterfly project has been monitoring all of these channels, and adding the data to their database.

Another example of the use of social media to encourage participation in a group project is the Alberta Winter Bug Count, with no sponsoring organisation in particular. This project began as an attempt to compare the diversity of active arthropods (indoors or out) to the diversity of birds seen in Alberta during December, January, and February each winter. Birders typically document about 140 species, and the arthropod counters find about 120 species. Records have been solicited from three list-servers (Albertaleps, Albertabugs, and ENCmembers - the list for the Edmonton Nature Club). As well, three Facebook pages are used to solicit reports (Winterbugs Alberta, Alberta Bugs and Insects, and The Alberta Lepidopterists' Guild). As with the butterfly Roundup, some observers prefer to report directly to me as compiler, or bring me specimens in person. What we have learned, I believe, is that with projects of this nature, it is unwise to attempt to force participants to use a particular data portal, and much more effective to take advantage of methods that are comfortable to them. Many participants are older, and somewhat averse to learning new computer skills. At the very least, this is the common self-identified reason given for their behaviour. As more tech-savvy individuals reach retirement age, perhaps this will become less of a constraint, or perhaps the technology of the future will be just as confusing to these people as the current technology is to today's senior citizen scientists.

\section{Crowdsourcing}

Yet another approach to citizen science involves crowdsourcing, and in particular the use of volunteers to transcribe specimen data labels. The "Notes from Nature" project (Hill et al. 2012) is one such example (with Canadian participation through the E. H. Strickland Entomological Museum at the University of Alberta, Edmonton, Alberta, Canada), as is the Smithsonian Transcription Center (https://transcription.si.edu/), and Entomology Translator (on Twitter@Ento Translator). To facilitate digitisation of collection data, specimens are photographed next to their data labels, and these images are made available online. Participants transcribe the label data, an activity that many find intrinsically enjoyable. Interpretation of hand-written labels is often challenging, as is the identification of obscure localities, especially if the label contains only a local name, without any broader geographic context.

Another example of citizen science crowdsourcing is the use of volunteers to help align DNA sequence data in a project named Phylo, with both Canadian and American involvement (Kowrykow et al. 2012). Apparently, the human mind is better than existing automatic algorithms when it comes to recognising long patterns in such sequences. Clearly, crowdsourcing projects of this nature illustrate that not all citizen science requires awareness on the part of the participants of the nature of the inquiry in which they are involved. For many, the tasks appear to be simple busywork, motivated by the idea that there will ultimately be some benefit to science at a higher level. However, Kowrykow et al. (2012) refer to their participants as "game players", and perhaps this phrase also characterises those who enjoy transcribing label data. Thus, it makes sense that citizen science participants do not necessarily learn much about science, or natural history, in the process (Druschke and Seltzer 2012), despite early evidence that eBird participants do engage in scientific habits of thought (Trumbull et al. 2000).

\section{Characteristics of successful citizen science projects}

How do we know if a particular citizen science project has been a success? It might seem obvious that the answer must lie in publications in the primary literature based on citizen science data data that could not be obtained in other ways. Unfortunately, such studies are, at least so far, few 
and far between, but they do exist. For example, citizen science databases have been used in countries outside Canada to analyse scale-dependent effects on temporal changes in syrphid fly species richness in the Netherlands and the United Kingdom (Keil et al. 2010), to predict the distribution of an introduced bee in Japan (Kadoya et al. 2009), to update the distribution of a coccinellid beetle in the United States of America (Smythe et al. 2013), and to elucidate broad patterns of pollinator abundance in France (Deguines et al. 2012). Canadian examples are, to my knowledge, confined to analyses of speed of migration as documented by eButterfly (Prudic et al. 2017).

It is, however, common to see citizen science projects credited with very particular discoveries, rather than the elucidation of broad patterns (e.g., records of a rare katydid (Orthoptera: Tettigoniidae), reported in Cannings et al. 2007), and anyone interested in species distributions must now consider citizen science databases in the course of their research. For example, I made extensive use of eButterfly while working on a recent field guide (Acorn and Sheldon 2016), and records from citizen science projects have been used in the Committee on the Status of Endangered Wildlife in Canada assessments of Canadian bumble bees (e.g., Committee on the Status of Endangered Wildlife in Canada 2015). With the rise of citizen science, monographlength projects of the type produced by the Biological Survey of Canada can also make use of citizen scientists' observations and photographs, when assessing the details of insect natural history (e.g., Shorthouse and Floate 2010), at least for those taxa for which such records exist. As citizen science databases are increasingly considered legitimate sources of information, they will likely be cited more frequently as well. As with research collections, the value of individual records may constitute the primary contribution of citizen science monitoring data - to help elucidate geographic ranges, changes in ranges, changes in phenology, and noteworthy incidental records. This may not sound like as lofty a goal as is the accumulation of a database capable of "monitoring" an entire fauna, but it is still a worthy objective.

Assessing citizen science in terms of publications is, however, predicated on the notion that citizen science projects exist in order to serve the needs of researchers and the scientific record. Since many citizen science projects exist in order to serve both researchers and participants, an additional criterion for the success of such projects might be the number of participants involved, or the longevity of the project. A project that continues to attract participants year after year is clearly a success in the eyes of those involved, regardless of what the project contributes to the scientific literature. Such projects, in my judgement, are characterised by the leadership efforts of particular key individuals, as well as the achievement of a "critical mass" of participants, making the database interesting to all concerned. As with field guides and other identification resources, there is always a trade-off between broad geographic coverage and focus on a particular local fauna. The best projects allow the user to switch effortlessly between the two.

There is a third group whose motives are also relevant to citizen science; the paid coordinators of citizen science projects, working for public institutions. These people may not be researchers themselves, or even naturalists. Instead, they may be office workers, employed to fulfil the institutional mandate, providing citizen science projects as a public service. In such instances, the success of the project will naturally be measured in corporate or institutional terms. Institutions typically like to see themselves as central, with a coordinating or leadership role. This can be achieved by incorporating data from smaller projects and thereby increasing the "metrics" of the larger project. Ultimately, though, such initiatives cannot avoid competing with the smaller projects, especially with regards to the volunteer efforts of expert vetters. Should entomologists with taxonomic expertise (assuming they have the time) help vet records at BugGuide, iNaturalist, eButterfly, or any of a myriad of smaller projects or social media sites? Surely, genuine expertise in insect identification is a limiting resource. Likewise, when one project shares data with another, participants need to choose which project to go to with their contributions. When I see a noteworthy butterfly, do I go to eButterfly, or do I go directly to iNaturalist, and most importantly, what are the consequences of this decision for the future of both projects?

It is easy to imagine a small citizen science project losing motivation as it is over-shadowed 
or even subsumed by a larger project, but it is also easy to imagine that a larger project with more institutional support might do a better job of pleasing both participants and research users in the long run. Like entomological journals, a spectrum of citizen science projects has emerged, with huge, well-funded examples on one end, and small, local, grass-roots examples on the other. Hopefully, projects all along this spectrum can continue to flourish.

Participation in citizen science projects may also conflict with the pre-existing data gathering habits of naturalists. Speaking for myself, this is a major issue. I carry a small notebook with me in the field, in which I write my observations. I then enter these observations into a set of field notes that I keep on my computer (these date back to notes transcribed from the early 1970s, when I was a child, and for this reason I am reluctant to break their continuity). For specific projects, I also enter data into spreadsheets, to facilitate analysis. Thus, when I encounter a particular butterfly in the course of a Pollard transect that I have been monitoring since 1998 , by the time I enter the observation in eButterfly it has been transcribed at least four times (and more if I reported it on a list-server, or social media site). Some might argue that I should enter data directly into a citizen science project via my smart phone in the field, and recover the data after the fact, but I suspect that many naturalists and researchers share in my hesitation to do so, in part for fear of losing data if the project is terminated. In the event that a citizen science project does come to an end, continued access to the resultant database is also a clear measure of success, even if the data sits unused for a prolonged period. In this regard, multiple back-ups of the database serve to protect against both mechanical and institutional catastrophes, in the sense that policies, priorities, and budgets may change over time.

For those interested in applied ecology and management, the measure of success in citizen science is the degree to which data are used by policy makers to effect changes in regulations, or leads to positive environmental changes in other ways. Despite a recent review of this issue (Conrad and Hilchey 2011), the extent to which this is the case remains unclear. One might ask, do citizen science projects shape public opinion and policy, or do they arise as a consequence of public opinion and policy? In the case of entomological projects, at least in Canada, the latter seems more likely, but this should not preclude the possibility of the former.

Finally, the success of a citizen science project must be measured, at least in part, in terms of the quality of the data obtained (Dickinson et al. 2010; Kremen et al. 2011; Gardiner et al. 2012) the extent to which professional researchers accept this data (Ottinger 2010), and the quality of the database cyber-architecture itself (Newman et al. 2011). Study design is important to working ecologists, but most citizen science projects are opportunistic in nature, such that there really is no study design other than the monitoring a specific aspect of nature. However, biases arising from selective reporting and non-standardised search effort are correctable through the use of occupancy models (van Strien et al. 2013). Additionally, when certain conditions are met, there are indeed statistical solutions that account for some types of error and bias in citizen science data (Bird et al. 2014; Isaac et al. 2014).

Most concerns about data quality, however, relate to identifications, not study design. In cases where a photograph or specimen is retained as a voucher, such errors can be corrected after the fact, but many citizen science projects involve no such safeguards. Inevitably, errors accumulate in any such database, and solutions to this problem are not simple. Ultimately, accurate identification will be based on the careful application of reliable identification resources, but they are also contingent upon the experience and integrity of the participant, both of which are left uncontrolled by citizen science organisers (with some exceptions, e.g., Bonter and Cooper 2012). BugGuide remains an excellent example of how this problem has been solved (since it uses photographs alone), but it does compromise data quantity for data quality. For eButterfly, and similar projects, expert local vetters attempt to control for errors. Encouragingly, it has been pointed out that data from citizen scientists is often as good or better than that gathered by paid assistants (Droege 2007).

In general, we can ask: has the idea of entomological citizen science as a whole been successful, and in particular, has it been successful in Canada? In terms of particular discoveries, enhanced resolution of geographic ranges and 
phenology, public participation, and endurance, the answer is clearly "yes". With respect to publications based on broad-scale analysis of citizen science data, perhaps it is too early to expect many analyses of trends, although Prudic et al. (2017) report that, "new collaborations and opportunities are on the horizon". It is worth keeping in mind that citizen science projects allow long-term data collection, on a temporal scale quite unlike the usual two to three-year studies performed by graduate student researchers or many government research projects. Participation in citizen science inspires people to an interest in natural history, and as a result we can anticipate more, and more diverse entomological citizen science in the future.

\section{The future of citizen science entomology in Canada, and the role of the Biological Survey of Canada}

Clearly, much of entomological citizen science in Canada has the same goal as the Biological Survey of Canada (BSC) - to generate insect biodiversity data. The 40th anniversary of the BSC provides an opportunity to reflect on the role that the BSC might play in the emerging citizen science scene in Canada. At the very least, the activities of those involved in the BSC have been and will continue to be enhanced by the availability of citizen science records, and the BSC should, in turn, make itself known to citizen scientists, who may wish to become members, and perhaps to become more deeply involved.

I will conclude, however, with a caution. In my opinion, the primary contribution of the BSC to entomology in Canada is to provide a high quality, peer-reviewed publication outlet for entomological works of a faunistic nature. In recent years, however, the BSC has added the Biota of Canada initiative to its activities (http://biologicalsurvey.ca/pages/read/the-biota-ofcanada), with the goal of coordinating various biologists, including non-entomologists, to produce an account of the species level biodiversity of the whole of Canada. This is a lofty goal, and it has the potential to place the BSC in a lofty position. There may be a natural tendency for a group that sees itself as having a central, coordinating role in biodiversity studies to also feel and obligation to help coordinate citizen science.
My advice, however, is to recognise that small citizen science projects are motivated idiosyncratically, at the grass-roots level (and therefore may do best if left to their own devices), while large projects may see the BSC as a competing institution (and may well possess greater resources than does the BSC). In my opinion, the BSC represents a collection of potential high-end research users for citizen science data, and in that sense the BSC helps justify the effort that organisers put into their particular projects. This point should be widely communicated. However, if members of the BSC wish to initiate new projects, with or without the support of the BSC as a whole, I hope that the ideas presented in this paper will help improve their chances for overall success.

\section{Acknowledgements}

I would like to acknowledge the things I have learned about citizen science from the Alberta Lepidopterists' Guild, and the participants in the Alberta winter bug count, and thank Héctor Cárcamo, Donna Giberson, Maxim Larrivée, and Felix Sperling and for help during the preparation of this paper. Two anonymous reviewers made suggestions that improved the manuscript significantly, by forcing me to tie up a number of conceptual loose ends.

\section{References}

Acorn, J.H. 2007. Ladybugs of Alberta: finding the spots and connecting the dots. University of Alberta Press, Edmonton, Alberta, Canada.

Acorn, J.H. 2016. Alberta butterfly roundup 2016 update. Alberta Lepidopterists' Guild Newsletter, 2016: 8-14.

Acorn, J.H. and Sheldon, I. 2016. Butterflies of Ontario and eastern Canada. Partners Publishing, Edmonton, Alberta, Canada.

Ball, S.G. and Morris, R.K.A. 2000. Provisional atlas of British hoverflies (Diptera: Syrphidae). Biological Records Centre, Huntingdon, United Kingdom.

Bell, S., Marzano, M., Cent, J., Kobierska, H., Podjed, D., Vandzinskaite, D., et al. 2008. What counts? Volunteers and their organizations in the recording and monitoring of biodiversity. Biodiversity Conservation, 17: 3443-3454.

Bird, C. 2016. Dry Island butterfly count, July 3, 2016. Alberta Lepidopterists' Guild Newsletter, 2016: 24-26.

Bird, T.J., Bates, A.E., Lefcheck, J.S., Hill, N.A., Thomson, R.J., Edgar, G.J., et al. 2014. Statistical solutions for error and bias in global citizen science datasets. Biological Conservation, 173: 144-154. 
Bonney, R., Cooper, C.B., Dickinson, J., Kelling, S., Phillips, T., Rosenburg, K.V., and Shirk, J. 2009. Citizen science: a developing tool for expanding science knowledge and scientific literacy. Bioscience, 59: 977-984.

Bonter, D.N. and Cooper, C.B. 2012. Data validation in citizen science: a case study from Project Feeder Watch. Frontiers in Ecology and the Environment, 10: 305-307.

Cannings, R.A., Miskelly, J.W., Schiffer, C.A.H., Lau, K.L.A., and Needham, K.M. 2007. Meconema thalassinum (Orthoptera: Tetigoniidae), a foreign katydid established in British Columbia. Journal of the Entomological Society of British Columbia, 104: 91-92.

Carlson, J.C., Fox, M.S., and McClarin, J. 2012. Passive surveillance in medical entomology using BugGuide. American Entomologist, 12: 645-651.

Colla, S.R. and Ratti, C.M. 2010. Evidence for the decline of the western bumble bee (Bombus occidentalis Greene) in British Columbia. The Pan-Pacific Entomologist, 86: 32-34.

Committee on the Status of Endangered Wildlife in Canada. 2015. COSEWIC assessment and status report on the yellow-banded bumble bee Bombus terricola in Canada. Committee on the Status of Endangered Wildlife in Canada, Ottawa, Ontario, Canada.

Conrad, C.C. and Hilchey, K.G. 2011. A review of citizen science and community-based environmental monitoring: issues and opportunities. Environmental Monitoring and Assessment, 176: 273-291.

Davis, M.A. and Chew, M.K 2017. 'The denialists are coming!' Well, not exactly: a response to Russell and Blackburn. Trends in Ecology and Evolution, 32: 229-230.

Deguines, N., Julliard, R., de Flores, M., and Fontaine, C. 2012. The whereabouts of flower visitors: contrasting land-use preferences revealed by a country-wide survey based on citizen science. Public Library of Science One, 7: e45822. https://doi.org/10.1371/ journal.pone.0045822.

Dickinson, J.L., Zuckerberg, B., and Bonter, D.N. 2010. Citizen science as an ecological research tool: challenges and benefits. Annual Review of Ecology, Evolution, and Systematics, 41: 149-172.

Droege, S. 2007. Just because you paid them doesn't mean their data are better. Citizen Science Toolkit Conference, June 20-23, 2007 [online]. Available from www.birds.cornell.edu/citscitoolkit/conference/ proceeding-pdfs/Droege \%202007\%20CS\%20Con ference.pdf [accessed 27 May 2017].

Druschke, C.G. and Seltzer, C.E. 2012. Failures of engagement: lessons learned from a citizen science pilot study. Applied Environmental Education and Communication, 11: 178-188.

Gardiner, M.M., Allee, L.L., Brown, P.M.J., Losey, J.E., Roy, H.E., and Smyth, R.R. 2012. Lessons from lady beetles: accuracy of monitoring data from US and UK citizen science programs. Frontiers in Ecology and the Environment, 10: 471-476.
Grixti, J.C., Wong, L.T., Cameron, S.A., and Favret, C. 2009. Decline of bumble bees (Bombus) in the North American Midwest. Biological Conservation, 142: 75-84.

Guiney, M.S. and Oberhauser, K.S. 2008. Insects as flagship conservation species. Terrestrial Arthropod Reviews, 1: 111-123.

Hamilton, K.G.A. 2011. What have we learned from shutterbugs? American Entomologist, 57: 102-109.

Hill, A., Guralnick, R., Smith, A., Sallans, A., Gillespie, R., Denslow, M., et al. 2012. The notes from nature tool for unlocking biodiversity records from museum records through citizen science. ZooKeys, 209: 219-233. https://doi.org/10.3897/zookeys.209.3472.

Holmes, A.M., Hess, Q.F., Tasker, R.R., and Hanks, A.J. 1991. The Ontario butterfly atlas. Toronto Entomologists' Association, Toronto, Ontario, Canada.

Isaac, N.J.B., van Strien, A.J., August, T.A., deZeeuw, M.P., and Roy, D.B. 2014. Statistics for citizen science: extracting signals of change from noisy ecological data. Methods in Ecology and Evolution, 5: $1052-1060$.

Kadoya, T., Ishii, H.S., Kikuchi, R., Suda, S., and Wahitani, I. 2009. Using monitoring data gathered by volunteers to predict the potential distribution of the invasive alien bumblebee Bombus terrestris. Biological Conservation, 142: 1011-1017.

Keil, P., Biesmeijer, J.C., Barendregt, A., Reemer, M., and Kunin, W.E. 2010. Biodiversity change is scale-dependent: an example form Dutch and UK hoverflies (Diptera: Syrphidae). Ecography, 33: 1-10.

Kowrykow, A., Roumanis, G., Kam, A., Kwak, D., Leung, C., Wu, C., et al. 2012. Phylo: a citizen science approach for improving multiple sequence alignment. Public Library of Science One, 7: e31362. https://doi.org/10.1371/journal.pone.0031362.

Kremen, C., Ullmann, K.S., and Thorp, R.W. 2011. Evaluating the quality of citizen-science data on pollinator communities. Conservation Biology, 25: 607-617.

LeBaron, G. 2007. Audubon's Christmas bird count: from 19th century conservation action to 21st century citizen science. Citizen Science Toolkit Conference, 20-23 June. Available from www. birds.cornell.edu/citscitoolkit/conference/proceedingpdfs/LeBaron\%202007\%20CS\%20Conference.pdf [accessed 27 May 2017].

Losey, J., Allee, L., and Smyth, R. 2012. The Lost Ladybug Project: citizen spotting surpasses scientist's surveys. American Entomologist, 58: 22-24.

Miller-Rushing, A., Primack, R., and Bonney, R. 2012. The history of public participation in ecological research. Frontiers in Ecology and the Environment, 10: $285-290$.

Moskowitz, D. and Haramaty, L. 2013. National Moth Week - a new global citizen science project focused on moths. Terrestrial Arthropod Reviews, 6: 185-200. 
Mueller, M., Tippins, D., and Bryan, L. 2012. The future of citizen science. Democracy and Education, 20: $1-12$.

Newman, G., Graham, J., Crall, A., and Laituri, M. 2011. The art and science of multi-scale citizen science support. Ecological Informatics, 6: 217-277.

Oberhauser, K.S. and Prysby, M.D. 2008. Citizen science: creating a research army for conservation. American Entomologist, 54: 97-99.

Ottinger, G. 2010. Buckets of resistance: standards and the effectiveness of citizen science. Science, Technology, and Human Values, 35: 244-270.

Pocock, R.H.E., Preston, C.D., Roy, D.B., Savage, J., Tweddle, J.C., and Robinson, L.D. 2012. Understanding citizen science and environmental monitoring. United Kingdom Environmental Observation Framework. The Natural History Museum, London, United Kingdom.

Prudic, K.L., McFarland, K.P., Oliver, J.C., Hutchinson, R.A., Long, E.C., Kerr, J.T., and Larrivée, M. 2017. eButterfly: leveraging massive online citizen science for butterfly conservation. Insects, 8: 53. https://doi.org/10.3390/insects8020053.

Pyle, R.M. 1984. Handbook for butterfly watchers. Houghton Mifflin, Boston, Massachusetts, United States of America.

Russell, J.C. and Blackburn, T.M. 2017. The rise of invasive species denialism. Trends in Ecology and Evolution, 32: 3-6.
Shorthouse, J.D. and Floate, K.D. (editors). 2010. Arthropods of Canadian grasslands: ecology and interactions in grassland habitats, volume 1. Biological Survey of Canada, Ottawa, Ontario, Canada.

Smythe, R.R., Allee, L.L., and Losey, J.E. 2013. The status of Coccinella undecimpunctata (L.) (Coleoptera: Coccinellidae) in North America: an updated distribution from citizen science data. The Coleopterists Bulletin, 67: 532-525.

Sullivan, B.L., Aycrigg, J.L., Barry, J.H., Bonney, R.E., Bruns, N., Cooper, C.B., et al. 2014. The eBird enterprise: an integrated approach to development and application of citizen science. Biological Conservation, 169: 31-40.

Trumbull, D.J., Bonney, R., Bascom, D., and Cabral, A. 2000. Thinking scientifically during participation in a citizen science project. Science Education, 84: 265-275.

van Strien, A.J., van Swaay, C.A.M., and Termaat, T. 2013. Opportunistic citizen science data of animal species produce reliable estimates of distribution trends if analyzed with occupancy models. Journal of Applied Ecology, 50: 1450-1458.

Wiggins, A. and Crowston, K. 2011. From conservation to crowdsourcing: a typology of citizen science. Hawai'i International Conference on System Science, 4: 2764-2773. 